\title{
Predictors of Parenting Stress During Early Adoptive Parenthood
}

\author{
Elena Canzi ${ }^{1}$ - Sonia Ranieri ${ }^{1} \cdot$ Daniela Barni $^{2} \cdot$ Rosa Rosnati $^{1}$
}

Published online: 7 August 2017

(C) The Author(s) 2017. This article is an open access publication

\begin{abstract}
Parenting stress has a crucial influence on the parent-child relationship, the functioning of the family, and the development of children. Few studies have examined parenting stress in adoptive families during early parenthood, and fewer still have considered this issue in association with the quality of both couple and social relationships. The current study was intended to investigate predictors of parenting stress in a community sample of 56 adoptive parents from Italy, for a total of 112 participants. Our goals were to: 1) evaluate parenting stress among adoptive parents during the first postadoption year, and 2) identify whether and to what extent parenting stress can be predicted by certain characteristics of the child (gender, age at adoption, years of institutionalisation, presence/absence of disease on arrival, emotional and behavioural difficulties), of parents' individual well-being (e.g., the presence of depressive symptoms), of relationships within the couple (sexual satisfaction, tenderness between partners, quarrelling) and with the social context (real and potential social support). In the analyses parents' gender effect and intercorrelations between the partners were taken into account. Results of multiple regression analysis and relative weight analysis highlighted the great importance of children's age at adoption and their emotional and behavioural difficulties in predicting both mothers' and fathers' stress, but also the
\end{abstract}

Daniela Barni

d.barni@lumsa.it

1 Family Studies and Research University Centre, Catholic University of Milan, Milan, Italy

2 Department of Human Sciences, LUMSA University of Rome, Piazza delle Vaschette, 101, 00193 Rome, Italy contribution of the couple relationship quality as a protective factor that could reduce the level of parenting stress.

Keywords Adoptive parents · Adoptive parenthood · Parenting stress $\cdot$ Couple relationship

\section{Introduction}

To become parents is a crucial family transition accompanied by changes in a couple's psychological well-being, relationship quality, and social network relationships (Ceballo et al. 2004; Cowan and Cowan 2000; Doss et al. 2009; Simpson et al. 2003). It implies the redefinition of the couple's roles and identity, as well as the beginning of a process involving inevitable personal, marital, family, and social changes (Cigoli and Scabini 2006). This phase in the lifecycle can therefore induce psychological distress, especially when the resources available to parents are perceived as inadequate to meet the challenges connected with their new roles.

Several studies have highlighted that parenting stress, defined as an "aversive psychological reaction to the demands of being a parent" (Deater-Deckard 1998, p. 315), is a risk factor affecting the children's psychological development, as it interferes with the parents' caregiving capacity, causing dysfunctional interactions and influencing the family's overall functioning (Abidin 1990; Greenley et al. 2006; Webster-Stratton 1990).

Adoptive parents find themselves facing additional challenges that make them particularly vulnerable to stress: in most cases, they have faced infertility (Cohen et al. 1993; Daniluk and Hurtig-Mitchell 2003) and become parents rather late in life (Ceballo et al. 2004); besides, they often find themselves having to cope with children who are emotionally and behaviourally difficult due to their past history of neglect, 
institutionalisation and sometimes abuse. The literature has documented that, on arrival, most adoptive children are in precarious physical and psychological conditions, displaying frequent medical problems (Johnson et al. 1992) and delays in their motor, cognitive (Canzi et al. 2017; Pomerleau et al. 2005) and socio-emotional development (van Londen et al. 2007).

Therefore, the transition to adoptive parenthood is particularly critical and requires specific developmental tasks. Whereas the title of parents is formally conferred by the court, both parents also have to legitimize each other (Cigoli and Scabini 2006). It means that they must engage themselves in an inner reciprocal legitimation process, the so-called entitlement process (Cohen et al. 1996), where they assume their new role as parents of that particular child, fully acknowledging his/her history and origins.

The data provided by the literature so far differ on the nature and the extent of parenting stress within adoptive families (McKay et al. 2010). According to some studies, adoptive parents report higher levels of stress than biological ones (McGlone et al. 2002; Paley et al. 2006; Rijk et al. 2006); other studies, however, have reported lower levels of stress in adoptive parents than those found in the normative population (Bird et al. 2002; Ceballo et al. 2004; Judge 2003; LevyShiff et al. 1990; Palacios and Sanchez-Sandoval 2006). This discrepancy shows a need for further research. Also factors that could contribute or hinder the levels of parenting stress need to be deeper investigated.

Most of the adoption literature is focused on the child's characteristics as predictors of parenting stress, suggesting that the older the child, the higher the parenting stress, in relation to the child's longer exposure to disadvantageous situations (Goldberg and Smith 2014; Nickman et al. 2005). Many studies have documented that later placement and prolonged institutionalisation are associated with more negative outcomes for children in all the main areas of development (Fox et al. 2011; Miller et al. 2009; Nelson et al. 2007), indicating the critical importance of considering these variables in association with parenting stress. Also, parents' perceptions of their children's emotional and behavioural difficulties are positively related to parenting stress: parents who perceive more problems in their child show more stress in playing their role (Goldberg and Smith 2014; Judge 2003; Mainemer et al. 1998; McGlone et al. 2002; Miller et al. 2009; Rijk et al. 2006; Viana and Welsh 2010). Finally, some authors have suggested that parents of international adopted children may experience more stress than parents of domestic adopted children, coming from child's early adversities (McGuinness and Pallansch 2000). But, as far as the differences between domestic and international adoptions are taken into account, there is no empirical evidence of a difference in the levels of parenting stress (Goldberg and Smith 2014).
Besides, the individual characteristics of parents have proved to be significantly related to parenting stress. As largely documented in studies on biological families (Chang and Fine 2007; Saisto et al. 2008), parents affected by mental problems, particularly depression, tend to display high levels of parenting stress. Some longitudinal studies on adoptive parents (Goldberg and Smith 2014; Viana and Welsh 2010) have shown that high depression levels prior to adoption predict higher levels of parenting stress in the post-adoption period.

Studies carried out on general population revealed that the quality of the couple's relationship and perceived social support may be important resources in contrasting parenting stress (Deater-Deckard 2004), but in the adoption literature these factors are still underestimated. Recently two studies concerning adoptive parents (Goldberg and Smith 2014; Salcuni et al. 2015) have documented the relationship between quality of the couple relationship and parenting stress, suggesting that couples who are more satisfied and show better dyadic functioning can expect lower levels of parenting stress. As far as the social support is considered, results are inconsistent. According to Viana and Welsh (2010), the parenting stress experienced by adoptive mothers is not associated with social support, while in Goldberg and Smith's study (2014) the support from friends and family perceived by the parents in the pre-adoption period is significantly, and negatively, associated with immediate post-adoption levels of stress.

There is a paucity of studies in the adoption literature that jointly examined children's characteristics, parents' individual well-being, and couple and social dimensions as predictors of post-placement parenting stress. Moreover, it is worth noting that in most studies the perception of only one parent was considered, but research on the general population had revealed that maternal and paternal perceptions of parenting stress may be significantly different and show differential prediction patterns (Saisto et al. 2008). In line with previous studies that have highlighted similarities, as well as differences within adoptive couples (Ferrari et al. 2015; Rosnati et al. 2008; Rosnati et al. 2013), both the mother and the father for each family should be considered to deeper understand the nature of parenting stress in this particular family transition. Furthermore, according to a family relational perspective (Cigoli and Scabini 2006), mothers and fathers are in constant interaction and their perceptions are reciprocally influenced. Despite evidence suggesting that parenting behaviour may be interdependent within marital couples, no studies to our knowledge have considered this interdependence within adoptive couple relationship, measuring the reciprocal influence between the scores of the dyad members on parenting stress.

The present study has an explorative intent and has the following aims: 1) to evaluate parenting stress among adoptive parents during the first post-adoption year, comparing mothers' and fathers' perceptions to each other and with a 
normative Italian sample; 2) to measure the importance of the following four dimensions in predicting parenting stress: a) children's characteristics (gender, age at adoption, years of institutionalisation, presence/absence of disease on arrival, emotional and behavioural difficulties), b) parents' individual well-being (i.e., the presence of depressive symptoms), c) the quality of the relationship within the couple (sexual satisfaction, tenderness between partners, quarrelling), and d) the relationship with the social context (i.e., real and potential social support). Parents' gender and intercorrelations between mothers' and fathers' perceptions were also taken into account.

\section{Method}

\section{Participants and Procedure}

The current research protocol was included in the follow up planned by a public adoption agency in Italy, Il Cerchio ASL Milano 1; as a consequence, all the families adopting a child from May 2012 to December 2013 participated in the study (with no rejection). Participants were 56 Caucasian married couples (112 total subjects) living in the North of Italy. ${ }^{1}$ The adoptive parents had been married for 10.24 years on average $(\mathrm{SD}=4.8)$, from a minimum of 2 to a maximum of 21 . On average, mothers were 43.28 years old $(\mathrm{SD}=4.27$; range $=34$ 55 years), and fathers were 44.05 years old $(S D=4.30$; range $=35-57$ years) .

Regarding the parents' level of education, $16 \%$ of the mothers and $28.6 \%$ of the fathers had a low educational level (primary school); $30.4 \%$ of the mothers and $42.9 \%$ of the fathers had a medium educational level (secondary school); $53.6 \%$ of the mothers and $28.5 \%$ of the fathers had a high educational level (university or post-graduate).

Adopted children (46.4\% girls and $53.6 \%$ boys) were, on average, 4.25 years old ( $\mathrm{SD}=2.85$; range $=10-132$ months) when they were placed. The distribution by areas of origin was: Africa (Congo, Ethiopia, Kenya, Tanzania), 32.2\%; Asia (China, Thailand), 19.6\%; Eastern European countries (Bulgaria, Poland, Russian Federation, Ukraine), 17.8\%; South America (Bolivia, Brazil, Chile, Colombia), 14.3\%; Italy (domestic adoptions), $16.1 \%$. The majority $(N=49$, $87.5 \%$ ) of children were institutionalised before adoption, on average for a period of 29.47 months $(S D=23.75)$. On their arrival, $57.1 \%(N=32)$ of the children reported diagnosed diseases (e.g., parasitosis, viral infections, genetic diseases). Six families adopted siblings: in these cases, only data about the older siblings were considered.

\footnotetext{
${ }^{1}$ According to the current Italian law, only married couples are allowed to adopt a child.
}

Within two months from the children's arrival, parents were given two self-report questionnaires, one for the mother and one for the father: each parent was asked to complete his/ her respective questionnaire independently from his/her partner. Anonymity and data confidentiality were guaranteed. All parents took part in the study voluntarily, and gave informed consent.

\section{Measures}

The instrument used was a self-report questionnaire including the following scales. ${ }^{2}$

Parenting stress This was measured through the Parenting Stress Index Short Form (PSI-SF, Abidin 1995). The Italian translation and validation of the scale was carried out by Guarino et al. (2008); the normative sample was composed of 1352 parents, aged between 18 and 54 years, with children aged between 0 and 12 years. $28.6 \%$ of the parents had a low educational level (primary school); $52.9 \%$ of the parents had a medium educational level (secondary school); $11 \%$ of the parents had a high educational level (university or post-graduate); ( $7.5 \%$ non reported). We referred to this normative sample in our analyses. The scale consists of 36 items, subdivided into three sub-scales, each made up of 12 items (Parental Distress, Parent-Child Dysfunctional Interaction, and Difficult Child). Added up, they form a Total Stress scale (TS) providing an indication of the total level of stress perceived by the parents. The items in the Parental Distress (PD) sub-scale (e.g., 'I often feel I can't cope very well with situations') measure the sense of parental competence/incompetence and the stress level experienced by each parent. The items in the Parent-Child Dysfunctional Interaction (P-CDI) sub-scale (e.g., 'My child rarely does things for me that I find gratifying') measure the parent's perception that the child does not meet his/her expectations and that interactions with the child fail to strengthen the parental role. The items in the Difficult Child (DC) sub-scale (e.g., 'My child seems to cry and to be upset more than most children') measure the parent's perception of his/her own ease/difficulty in managing the child in relation to his/her behaviour and temperament. All items were rated on a five-point Likert scale ranging from 1 (strongly disagree) to 5 (strongly agree). In this study only the Total Stress scale was used, and it showed good internal consistency, both for mothers (Cronbach's alpha $=.88)$ and for fathers (Cronbach's alpha $=.88)$. The PSI-SF also allows the identification of

\footnotetext{
${ }^{2}$ Because all variables were collected by self-report scales from the same individual, we tested if common method bias (CMB) (cf. Bagozzi and Yi 1990; Campbell and Fiske 1959) was of concern in our study by calculating Harman's single factor score. Results suggested that the data suffered from CMB neither in the case of mothers' reports nor in fathers' reports. The total variance for the single factor score was indeed $14.2 \%$ for mothers' variables and $13.6 \%$ for fathers' variables, much lower than the critical value of $50 \%$.
} 
parents with clinically high stress levels, by using percentile cut-off points: scores at or above the 85th percentile are considered high and clinically significant (Abidin 1995).

Children's emotional and behavioural difficulties Adoptive parents' perceptions of their children's emotional and behavioural difficulties were assessed by the parent version of the Strengths and Difficulties Questionnaire (SDQ, Goodman 1997; Italian norms and translation available on www.sdqinfo.org). This scale consists of 25 items relating to five dimensions made up of 5 items each (i.e., Emotional Problems, Conduct Problems, Hyperactivity, Peer Relationship Problems, and Prosocial Behaviour). In this study, the total difficulties score was calculated by adding up the scores of 4 of the 5 subscales, that is, all except Prosocial Behaviour. A higher score indicates more difficulties. Sample items include: 'He/she is restless, hyperactive, unable to sit still for long' and ' $\mathrm{He} / \mathrm{she}$ is rather solitary, tends to play on his/her own'. All items were rated on a three-point Likert scale from 0 (not true) to 2 (certainly true). The scales showed good internal consistency, both for mothers (Cronbach's alpha $=.71$ ) and for fathers (Cronbach's alpha $=.69$ ).

Parental depression Parents' depression levels were measured through the Center for Epidemiological Studies Depression Scale (CES-D, Radloff 1977; Italian validation and translation published by Pierfederici et al. 1982), consisting of 20 items on a four-point Likert scale assessing the frequency of depressive symptoms during the previous week $(0=$ seldom or never, $1=$ sometimes or for a short time, $2=$ occasionally or for a limited time, $3=$ often or all the time). Sample items included: 'I had little appetite' and "I slept restlessly'. The maximum score to distinguish between the presence and the absence of depressive symptoms was 16 out of 60 . The scales showed good internal consistency both for mothers (Cronbach's alpha $=.87$ ) and for fathers $($ Cronbach's alpha $=.75)$.

Couple relationship quality The quality of couple relationship was measured through the Partnership Questionnaire (PFB, Hahlweg 1996; Italian translation and validation published by Donato et al. 2014), made of 24 items on a four-point Likert scale (from $0=$ never to 3 = always), subdivided into three sub-scales (Sexuality, Tenderness and Quarrelling). Sexuality (4 items) assessed the couple's sexual satisfaction (e.g., 'I believe my husband/wife finds me physically attractive'); Tenderness (11 items) measured the interest and affection shared between partners (e.g., 'My husband/wife shares his/her thoughts and feelings with me'); Quarrelling (9 items) identified levels of aggressive, negative or disparaging behaviour between partners (e.g., 'My husband/wife looks down on my opinions'). All the sub-scales showed good internal consistency, both for mothers (Cronbach's alpha range $=.60-.89$ ) and for fathers (Cronbach's alpha range $=.70-.82$ ).

Social support Perceived social support was measured through the Social Relationship Questionnaire (Gigantesco et al. 1995), and particularly through two sub-scales: Real Support, made up of 4 items and measuring the actual availability of companionship and help (e.g., 'I easily find someone with whom I like to spend time'), and Potential Support, composed of 6 items and measuring the potential availability of companionship and help (e.g., 'When I feel tense or worried I can find someone close'). All items were rated on a five-point Likert scale ranging from 1 (never) to 5 (always). The two sub-scales showed good internal consistency, both for mothers (Real Support: Cronbach's alpha $=.73$; Potential Support: Cronbach's alpha $=.86$ ) and for fathers (Real Support: Cronbach's alpha $=.70$; Potential Support: Cronbach's alpha $=.79$ ).

\section{Data Analyses}

Variables were first described in terms of means, standard deviations and range. To compare maternal and paternal perceptions of parenting stress a paired t-test between mothers' and fathers' scores was carried out. In order to compare parenting stress among adoptive parents with the normative Italian sample (Guarino et al. 2008), two one-sample t-tests were performed, one for mothers and the other for fathers. In the case of significant differences, we calculated Cohen's $d$ to measure the effect sizes.

Associations between the study variables were measured by bivariate Pearson correlations. In order to test how and the extent to which these variables contributed to predict parenting stress, two separate multiple regression models (MR), for, respectively, mothers' and fathers' Total Stress, were performed. The independent variables were those that turned out to be significantly correlated to parenting stress, including the partner's perceptions.

Through MR, we estimated the overall $\mathrm{R}^{2}$ and determined the statistical significance of individual regression coefficients. However, in order to take into account the intercorrelations between mothers' and fathers' variables, we supplemented MR with relative weight analysis (RWA) (Johnson 2000). RWA is a relatively new analytical strategy, which can complement traditional regression analysis in assessing the importance of conceptually and empirically correlated predictors (Barni 2015). If predictors are uncorrelated or orthogonal, standardized regression coefficients equal zero-order correlations, and if the squared regression coefficients are summed, they equal $\mathrm{R}^{2}$. However, when predictors are correlated - as the case of couple data - variance in the criterion that 
can be explained by multiple predictors is often not adequately divided among the predictors (Kraha et al. 2012).

RWA focuses on the impact of a particular predictor relative to others in the model: that is, the proportionate contribution each predictor makes to $\mathrm{R}^{2}$, taking into account both the unique relationship with the criterion and its relationship when combined with other predictors (i.e., relative contribution). It uses a variable transformation approach to address the issue of correlated predictors. Precisely, relative weights can be estimated by creating a set of variables that are highly related to the original one, but are uncorrelated with each other. The criterion variable can then be regressed on the new uncorrelated variables to approximate the relative weights of the original variables (for further details, see Johnson 2000). The importance weights provided by the analysis can then be scaled in the metric of relative effect size by dividing the relative weights by the model $\mathrm{R}^{2}$ and then multiplying these values by 100 . In this way, the rescaled weights are interpreted as the percentage of predicted criterion variance attributed to each predictor.

\section{Results}

Descriptive statistics for all the considered variables are shown in Table 1.

Total Stress scores were within the non-clinical range for respectively $92.9 \%$ of mothers $(N=52)$ and $91.1 \%$ of fathers $(N=51)$, with no significant differences between mothers $(\mathrm{M}=63.59, \mathrm{SD}=14.06)$ and fathers $(\mathrm{M}=63.09$, $\mathrm{SD}=12.80)[\mathrm{t}(55)=.270, p=\mathrm{n} . \mathrm{s}$. $]$. Adoptive parents, both mothers and fathers, scored significantly lower [mothers: $\mathrm{t}(55)=-3.264, p<.005$, Cohen's $\mathrm{d}=.88$; fathers: $\mathrm{t}(55)=-3.777, p<.001$, Cohen's $\mathrm{d}=1.02]$ than parents from the normative sample in the Total Stress scale $(M=69.72$, $\mathrm{SD}=17.11$ for mothers; $\mathrm{M}=69.55, \mathrm{SD}=19.69$ for fathers).

The correlations between the investigated variables are presented in Table 2. The mothers' Total Stress scores were significantly related to: some children's characteristics (age at adoption, and mothers' perceptions of the children's emotional and behavioural difficulties), maternal individual well-being, and relationship quality within the couple (mothers' quarrelling with the partner, fathers' tenderness between partners, and fathers' sexual satisfaction). Significant correlations were also found between fathers' Total Stress scores and some children's characteristics (age at adoption, fathers' and mothers' perceptions of the children's emotional and behavioural difficulties), and relationship quality within the couple (fathers' and mothers' tenderness between partners, fathers' sexual satisfaction).

As already mentioned, we conducted a preliminary MR separately for mothers' Total Stress and fathers' Total Stress (Table 3). The regression analyses were carried out in order to test the contribution of predictors to parents' Total Stress scores - those emerging as significantly related with the outcomes.

Overall, regression models demonstrated that a significant proportion of variance in mothers' Total Stress $\left[\mathrm{R}^{2}=.47 ; \mathrm{F}\right.$ $(6,49)=7.36, p<.001]$ and fathers' Total Stress $\left[\mathrm{R}^{2}=.42 ; \mathrm{F}\right.$ $(6,49)=5.97, p<.001]$ was explained by the predictors. Inspection of $\beta$ weights revealed that children's characteristics were significantly related to mothers' stress: the more the child was older at his/her arrival and was perceived by his/her mother as problematic, the higher was the mother's parenting stress. Similar results were found as far as fathers' levels of stress were concerned: the more the child was older at his/her arrival and was perceived by his/her father as problematic, the higher was the father's parenting stress.
Table 1 Means and standard deviations of variables in the study

\begin{tabular}{|c|c|c|c|c|}
\hline \multirow[t]{2}{*}{ Variables } & \multicolumn{2}{|l|}{ Mothers } & \multicolumn{2}{|l|}{ Fathers } \\
\hline & $\mathrm{M}(\mathrm{SD})$ & Range & $\mathrm{M}(\mathrm{SD})$ & Range \\
\hline Parenting stress & $63.59(14.06)$ & $5-100$ & $63.09(12.80)$ & $41-92$ \\
\hline \multicolumn{5}{|l|}{ Children's characteristics } \\
\hline Children's emot. and behav. diff. & $9.70(4.20)$ & $3-25$ & $9.31(4.20)$ & $1-20$ \\
\hline \multicolumn{5}{|l|}{ Parents' individual well-being } \\
\hline Parental depression & $9.41(6.74)$ & $0-26$ & $6.91(4.20)$ & $0-27$ \\
\hline \multicolumn{5}{|l|}{ Couple relationship quality } \\
\hline Sexuality & $8.2(2.05)$ & $4-12$ & $7.62(2.30)$ & $2-12$ \\
\hline Tenderness & $23.25(6.00)$ & $9-33$ & $20.02(5.13)$ & $7-28$ \\
\hline Quarrelling & $5.07(4.05)$ & $0-17$ & $7.28(3.30)$ & $2-18$ \\
\hline \multicolumn{5}{|l|}{ Social support } \\
\hline Real social support & $15.14(2.47)$ & $8-20$ & $13.37(2.58)$ & $9-20$ \\
\hline Potential social support & $25.02(3.80)$ & $14-30$ & $23.62(3.61)$ & $16-30$ \\
\hline
\end{tabular}




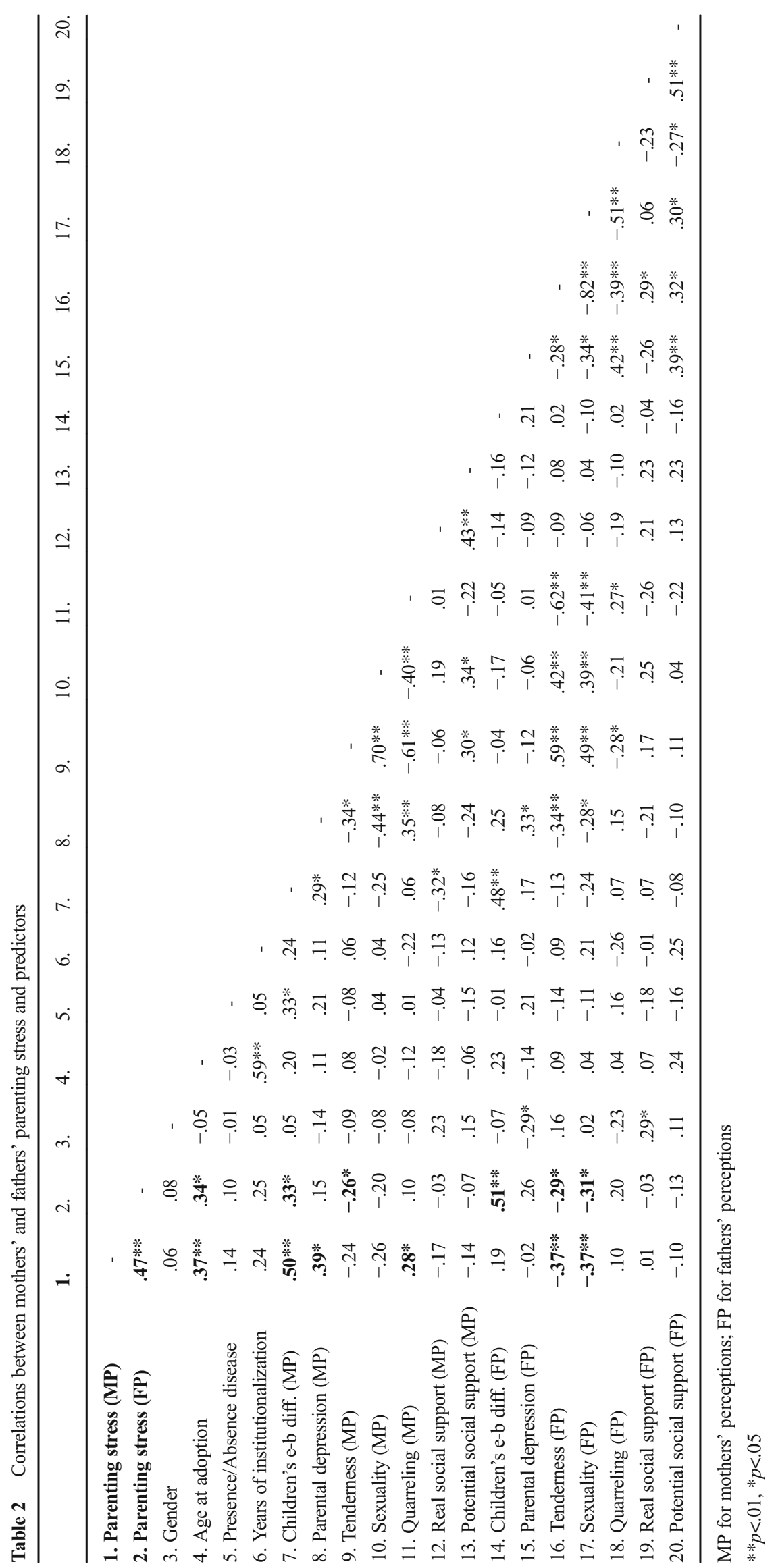


Table 3 MR and RWA with mothers' and fathers' parenting stress as dependent variables

\begin{tabular}{|c|c|c|c|c|}
\hline \multirow[t]{2}{*}{ Variables } & \multicolumn{2}{|l|}{ MR } & \multicolumn{2}{|l|}{ RWA } \\
\hline & $\beta$ & $\mathrm{p}$ & Raw importance & Rescaled importance $(\%)$ \\
\hline \multicolumn{5}{|l|}{ MOTHERS' PARENTING STRESS } \\
\hline Children's age & .32 & .005 & .12 & 25.2 \\
\hline Children's e-b difficulties (MP) & .35 & .003 & .16 & 34.7 \\
\hline Parental depression (MP) & .14 & .253 & .06 & 13.0 \\
\hline Quarrelling (MP) & .12 & .398 & .03 & 7.2 \\
\hline Tenderness (FP) & -.16 & .461 & .05 & 10.1 \\
\hline Sexuality (FP) & -.08 & .663 & .05 & 9.8 \\
\hline $\mathrm{R}^{2}$ & & & .47 & 100 \\
\hline \multicolumn{5}{|l|}{ FATHERS' PARENTING STRESS } \\
\hline Children's age & .26 & .024 & .09 & 21.0 \\
\hline Children's e-b difficulties (FP) & .43 & .001 & .19 & 44.0 \\
\hline Children's e-b difficulties (MP) & .02 & .859 & .04 & 9.5 \\
\hline Tenderness (FP) & -.23 & .272 & .04 & 10.1 \\
\hline Sexuality (FP) & -.03 & .886 & .03 & 7.7 \\
\hline Tenderness (MP) & -.11 & .403 & .03 & 7.7 \\
\hline $\mathrm{R}^{2}$ & & & .42 & 100 \\
\hline
\end{tabular}

MP for mothers' perceptions and FP for fathers' perceptions
The analysis of the relative contribution of each predictor in explaining parenting stress, through RWA, highlighted the importance of children's age at the adoption and of their emotional and behavioural difficulties, in accordance with the regression results (Table 3). These two variables together explained the largest portion of the variance of mothers' Total Stress $(59.9 \%)$ as well as of fathers' Total Stress $(65 \%)$.

Interestingly, RWA revaluated the contribution of the couple relationship variables, which gave a more substantial contribution to the explanation of parenting stress than that suggested by the analysis of $\beta$ weights and of statistical significance. The couple relationship variables explained the $27.1 \%$ of variance in the case of maternal stress and the $25.5 \%$ in the case of paternal stress. Among them, the most important predictor was fathers' perception of tenderness shared with the spouse, both for mothers' Total Stress and fathers' Total Stress.

\section{Discussion}

The present study was aimed at examining parenting stress in adoptive families during early parenthood, as well as investigating predictors of parenting stress by exploring four dimensions: adopted children's characteristics, parents' individual well-being, relationship quality within the couple and with the social context. The level of stress perceived by adoptive parents in relation to their parental role was, in the vast majority of cases, within the norm, with no significant differences between mothers and fathers. As emerged in previous studies
(Ceballo et al. 2004; Judge 2003; Goldberg and Smith 2014; Palacios and Sanchez-Sandoval 2006), soon after placement adoptive parents reported low stress levels, even lower than those found in the normative Italian sample (Guarino et al. 2008). As already suggested by Levy-Shiff et al. (1991), new adoptive parents seem to experience a 'honeymoon' period: this transition appears to have fewer negative effects than it has on biological parents, possibly because years of longing make adoptive parents feel more gratified by the rewards accompanying their new status, while they tend to underestimate the difficulties of taking care of their children and interacting with them. Although research on adoptive parents' stress trajectories is conflicting, we can suppose that the levels of stress could increase in the following years, as evidenced in recent literature (Goldberg and Smith 2014), highlighting the importance of prevention efforts. Thus, research with multidimensional approach would be useful to have a more complete portrait of this population during this particular period, to explore a wider range of risk and protective factors, and to early identify those parents who may struggle more in the future.

The study's second aim was to measure the contribution of four dimensions (i.e., children's characteristics, parents' individual well-being, couple and social relationship quality) in predicting parenting stress. In doing so, we also considered the impact of the partner's perceptions on each parent's stress in taking care of his/her children. Indeed, a comprehensive and enriched examination of parenting requires considering data of dyadic partners as interdependent (Barnett et al. 2008).

Our findings were consistent with previous studies: both the children's age at adoption (Goldberg and Smith 2014; 
Nickman et al. 2005) and the parents' perceptions of their children's emotional and behavioural difficulties (Judge 2003; Miller et al. 2009; Viana and Welsh 2010) were found to be related to parenting stress. Specifically, parents who perceive more problems with their child also display a greater stress in playing their parental role, and older adopted children are immediately perceived as more difficult and demanding. Even though age at adoption's influence might decrease in later stages (Palacios and Sanchez-Sandoval 2006; SanchezSandoval and Palacios 2013), in these first stages it seems to play a significant role.

Most interestingly, the RWA also highlighted the contribution of the quality of the relationship within the couple both for mothers' and fathers' parenting stress. The arrival of a child in the family involves a reorganisation phase and brings considerable changes to a couple's balance. Marital and parental bonds are inextricably connected and a good couple relationship quality seems to be crucial to the exercise of the parental role, enabling parents to face the challenges linked with childrearing. Among the couple relationship variables, fathers' perception of tenderness shared with the spouse was the most important predictor, both for mothers' and fathers' stress. Fathers' satisfaction about closeness with their partners makes both parents feel less stressed and more involved in the care of their children as well. On the other hand, we can suppose that the less satisfied fathers may tend to provide less support to their partners that as a consequence may be more stressed and overwhelmed.

As a matter of fact our findings revealed that adoptive mothers are more prone than fathers to be influenced by the quality of couple relationship as perceived by their partner.

This study has a number of limitations. First, the sample size was small, so caution is needed when extending findings to the general population of adoptive parents. Further studies on larger samples are necessary before any definite conclusions are drawn. Second, we used exclusively self-report measures: a multi-method approach to studying parenting is needed in order to gain a clearer picture of parenting processes and outcomes, and to reduce the self-report biases. Third, the study was cross-sectional, therefore causal relationship of the test variables cannot be established, since factors associated with stress might result as a consequence of stress experience, as well as a source of more stress. Longitudinal studies are needed to better disentangle cause-and-effect directions among the variables, and to observe trends of parenting stress across the lifespan. Finally, it would be important in further investigations to focus on clinical sample of adoptive parents, to better identify factors associated to parenting stress, highlighting the specific contribution of the individual, relational, and social predictors also in dysfunctional contexts.

Nevertheless, the results of the present study open up interesting research paths and offer insights as to possible interventions with adoptive families. A major strength of this research lies in that both parents were involved, which has enlightened the specific and unique, but interdependent, way in which fathers and mothers experience parenting. In fact, research has seldom been focused on the adoptive couple bond and the specific contribution offered by mothers and fathers to their relationship with an adoptive child (Rosnati et al. 2008). Future studies will hopefully follow this path by assuming a family-based perspective and involving both mothers and fathers. Designing successful family interventions indeed requires identifying more specifically which and how parent's behaviors and perceptions are driving the other parent's behaviors and perceptions (Barnett et al. 2008). Likewise, results suggest that, in pre- and post-adoption practice, attention should be devoted not just to the characteristics and the risk factors linked to the children and their history, but also to the quality of the couple relationship and those factors that may become stressful for parents during the initial stages of new parenthood, considering the different influence of these factors for both the mothers and the fathers.

Acknowledgements This article was supported by a grant from the LUMSA University of Rome, Italy. We would like to thank the adoption public agency Il Cerchio ASL Milano 1, the professionals who collaborated with this project and all the families who took part to the research.

\section{Compliance with ethical standards}

Conflict of Interest Elena Canzi declares that she has no conflict of interest. Sonia Ranieri declares that she has no conflict of interest. Daniela Barni declares that she has no conflict of interest. Rosa Rosnati declares that she has no conflict of interest.

Ethical approval All procedures performed in studies involving human participants were in accordance with the ethical standards of the institutional research committee and with the 1964 Helsinki declaration and its later amendments or comparable ethical standards.

Informed consent Informed consent was obtained from all individual participants included in the study.

Open Access This article is distributed under the terms of the Creative Commons Attribution 4.0 International License (http:// creativecommons.org/licenses/by/4.0/), which permits unrestricted use, distribution, and reproduction in any medium, provided you give appropriate credit to the original author(s) and the source, provide a link to the Creative Commons license, and indicate if changes were made.

\section{References}

Abidin, R. (1990). Introduction to the special issue: The stresses of parenting. Journal of Clinical Child Psychology, 19(4), 298-301.

Abidin, R. R. (1995). Parenting Stress Index Short Form: Test Manual. Charlottesville: Pediatric Psychology Press.

Bagozzi, R. P., \& Yi, Y. (1990). Assessing method variance in multitraitmultimethod matrices: The case of self-reported affect and perceptions at work. Journal of Applied Psychology, 75(5), 547-560. 
Barnett, M. A., Deng, M., Mills-Koonce, W. R., Willoughby, M., \& Cox, M. (2008). Interdependence of parenting of mothers and fathers of infants. Journal of Family Psychology, 22(3), 561-573.

Barni, D. (2015). The relative importance analysis for the study of the family: Accepting the challenge of correlated predictors. TPM Testing, Psychometrics, and Methodology in Applied Psychology, 22(2), 235-250.

Bird, G., Peterson, R., \& Miller, S. H. (2002). Factors associated with distress among support-seeking adoptive parents. Family Relations, 51(3), 215-220.

Campbell, D. T., \& Fiske, D. (1959). Convergent and discriminant validation by the multitrait-multimethod matrix. Psychological Bulletin, 56(2), 81-105.

Canzi, E., Rosnati, R., Palacios, J., \& Román, M. (2017). Internationally adopted children's cognitive and social-emotional development during the first post-adoption year: A longitudinal study. European Journal of Developmental Psychology. doi:10.1080/17405629. 2017.1316257.

Ceballo, R., Lansford, J., Abbey, A., \& Stewart, A. (2004). Gaining a child: Comparing the experiences of biological parents, adoptive parents and stepparents. Family Relations, 53(1), 38-48.

Chang, Y., \& Fine, M. A. (2007). Modeling parenting stress trajectories among low-income young mothers across the child's second and third years: Factors accounting for stability and change. Journal of Family Psychology, 21(4), 584-594.

Cigoli, V., \& Scabini, E. (2006). Family identity. Ties, symbols, and transitions. Mahwah: Lawrence Erlbaum Associates.

Cohen, N. J., Coyne, J., \& Duvall, J. (1993). Adopted and biological children in the clinic: Family, parental and child characteristics. Journal of Child Psychology and Psychiatry, 34(4), 545-562.

Cohen, N. J., Coyne, J. C., \& Duvall, J. D. (1996). Parents' sense of "entitlement" in adoptive and nonadoptive families. Family Process, 35(4), 441-456.

Cowan, C. P., \& Cowan, P. A. (2000). When partners become parents: The big life change for couples. Mahwah: Lawrence Erlbaum Associates.

Daniluk, J. C., \& Hurtig-Mitchell, J. (2003). Themes of hope and healing: Infertile couples' experiences of adoption. Journal of Counseling and Development, 81(4), 389-399.

Deater-Deckard, K. (1998). Parenting stress and child adjustment: Some old hypotheses and new questions. Clinical Psychology: Science and Practice, 5(3), 314-332.

Deater-Deckard, K. (2004). Parenting stress. London: Yale University Press.

Donato, S., Canzi, E., Parise, M., \& Ferrari, L. (2014). Partnership Questionnaire: Factorial structure, gender invariance, and concurrent validity. TPM - Testing, Psychometrics, Methodology in Applied Psychology, 21(2), 161-180.

Doss, B. D., Rhoades, G. K., Stanley, S. M., \& Markman, H. J. (2009). The effect of the transition to parenthood on relationship quality: An eight-year prospective study. Journal of Personality and Social Psychology, 96(3), 601-619.

Ferrari, L., Ranieri, S., Barni, D., \& Rosnati, R. (2015). Parent-child relationship and adoptees' psychological well-being in adolescence and emerging adulthood: Disentangling maternal and paternal contribution. Family Science, 6(1), 77-86.

Fox, N. A., Almas, A. N., Degnan, K. A., Nelson, C. A., \& Zeanah, C. H. (2011). The effects of severe psychosocial deprivation and foster care intervention on cognitive development at 8 years of age: Findings from the Bucharest Early Intervention Project. Journal of Child Psychology and Psychiatry, 52(9), 919-928.

Gigantesco, A., Rossi, L., Morosini, P., \& Flisi, E. (1995). QRS: A new measure to evaluate social support. Bollettino di Psicologia Applicata, $214,37-44$.
Goldberg, A. E., \& Smith, J. Z. (2014). Predictors of parenting stress in lesbian, gay, and heterosexual adoptive parents during early parenthood. Journal of Family Psychology, 28(2), 125-137.

Goodman, R. (1997). The Strengths and Difficulties Questionnaire: A research note. Journal of Child Psychology and Psychiatry, 38(5), $581-586$

Greenley, R. N., Holmbeck, G. N., \& Rose, B. M. (2006). Predictors of parenting behavior trajectories among families of young adolescents with and without spina bifida. Journal of Pediatric Psychology, 31(10), 1057-1071.

Guarino, A., Di Blasio, P., D’Alessio, M., Camisasca, E., \& Serantoni, M. (2008). Parenting Stress Index Short Form. Italian Validation. Florence: Giunti O.S. Organizzazioni Speciali.

Hahlweg, K. (1996). Fragebogen zur Partnerschaftsdiagnostik (FDP) [Partnership Questionnaire (PFB)]. Göttingen: Hogrefe.

Johnson, J. W. (2000). A heuristic method for estimating the relative weight of predictor variables in multiple regression. Multivariate Behavioral Research, 35(1), 1-19.

Johnson, D. E., Miller, L. C., Iverson, S., Thomas, W., Franchino, B., Dole, K., Kiernan, M. T., Georgieff, M. K., \& Hostetter, M. K. (1992). The health of children adopted from Romania. Journal of the American Medical Association, 268(24), 3446-3451.

Judge, S. (2003). Determinants of parental stress in families adopting children from Eastern Europe. Family Relations, 52(3), 241-248.

Kraha, A., Turner, H., Nimon, K., Reichwein Zientek, L. R., \& Henson, R. K. (2012). Tools to support interpreting multiple regression in the face of multicollinearity. Frontiers in Psychology, 3, 1-16.

Levy-Shiff, R., Bar, O., \& Har-Even, D. (1990). Psychological adjustment of adoptive parents-to-be. American Journal of Orthopsychiatry, 60(2), 258-267.

Levy-Shiff, R., Goldshmidt, I., \& Har-Even, D. (1991). Transition to parenthood in adoptive families. Developmental Psychology, 27(1), 131-140.

Mainemer, H., Gilman, L. C., \& Ames, E. W. (1998). Parenting stress in families adopting children from Romanian orphanages. Journal of Family Issues, 19(2), 164-180.

McGlone, K., Santos, L., Kazama, L., Fong, R., \& Mueller, C. (2002). Psychological stress in adoptive parents of special-needs children. Child Welfare, 81(2), 151-171.

McGuinness, T., \& Pallansch, L. (2000). Competence of children adopted from the former Soviet Union. Family Relations, 49(4), 457-464.

McKay, K., Ross, L. E., \& Goldberg, A. E. (2010). Adaptation to parenthood during the post-adoption period: A review of the literature. Adoption Quarterly, 13(2), 125-144.

Miller, L. C., Chan, W., Tirella, L., \& Perrin, E. (2009). Outcomes of children adopted from Eastern Europe. International Journal of Behavioral Development, 33(4), 289-298.

Nelson, C. A., Zeanah, C. H., Fox, N. A., Marshall, P. J., Smyke, A. T., \& Guthrie, D. (2007). Cognitive recovery in socially deprived young children: The Bucharest Early Intervention Project. Science, 318(5858), 1937-1940.

Nickman, S. L., Rosenfeld, A. A., Fine, P., MacIntyre, J. C., Pilowsky, D. J., Howe, R. A., et al. (2005). Children in adoptive families: Overview and update. Journal of the American Academy of Child \& Adolescent Psychiatry, 44(10), 987-995.

Palacios, J., \& Sanchez-Sandoval, Y. (2006). Stress in parents of adopted children. International Journal of Behavioral Development, 30(6), 481-487.

Paley, B., O'Connor, M. J., Frankel, F., \& Marquardt, R. (2006). Predictors of stress in parents of children with fetal alcohol spectrum disorders. Journal of Developmental \& Behavioral Pediatrics, 27(5), 396-404.

Pierfederici, A., Fava, G. A., Munari, F., Rossi, N., Baldaro, B., Pasquali Evangelisti, L., et al. (1982). Italian validation of the CES-D scale to measure depression. In R. Canestrari (Ed.), New methods in psychometrics (pp. 95-103). Florence: Organizzazioni Speciali. 
Pomerleau, A., Malcuit, G., Chicoine, J. F., Séguin, R., Belhumeur, C., Germain, P., et al. (2005). Health status, cognitive and motor development of young children adopted from China, East Asia, and Russia across the first 6 months after adoption. International Journal of Behavioral Development, 29(5), 445-457.

Radloff, L. S. (1977). The CES-D scale: A self-report depression scale for research in the general population. Applied Psychological Measurement, 1(3), 385-401.

Rijk, C. H., Hoksbergen, R. A., ter Laak, J. J., van Dijkum, C., \& Robbroeckx, L. H. M. (2006). Parents who adopt deprived children have a difficult task. Adoption Quarterly, 9(2-3), 37-61.

Rosnati, R., Montirosso, R., \& Barni, D. (2008). Behavioral and emotional problems among Italian international adoptees and nonadopted children. Father's and mother's reports. Journal of Family Psychology, 22(3), 541-549.

Rosnati, R., Ranieri, S., \& Barni, D. (2013). Family and social relationships and psychosocial well-being in Italian families with internationally adopted and non-adopted children. Adoption Quarterly, 16(1), 1-16.

Saisto, T., Salmela-Aro, K., Nurmi, J. E., \& HalmesmÄki, E. (2008). Longitudinal study on the predictors of parental stress in mothers and fathers of toddlers. Journal of Psychosomatic Obstetrics and Gynecology, 29(3), 219-228.
Salcuni, S., Miconi, D., Altoè, G., \& Moscardino, U. (2015). Dyadic adjustment and parenting stress in internationally adoptive mothers and fathers: The mediating role of adult attachment dimensions. Frontiers in Psychology. doi:10.3389/fpsyg.2015.01279.

Sanchez-Sandoval, Y., \& Palacios, J. (2013). Stress in adoptive parents of adolescents. Children and Youth Services Review, 34(7), 12831289.

Simpson, J. A., Rholes, W. S., Campbell, L., Tran, S., \& Wilson, C. L. (2003). Adult attachment, the transition to parenthood, and depressive symptoms. Journal of Personality and Social Psychology, 84(11), 72-1187.

van Londen, W. M., Juffer, F., \& van IJzendoorn, M. H. (2007). Attachment, cognitive, and motor development in adopted children: Short-term outcomes after international adoption. Journal of Pediatric Psychology, 32(10), 1249-1258.

Viana, A. G., \& Welsh, J. A. (2010). Correlates and predictors of parenting stress among internationally adopting mothers: A longitudinal investigation. International Journal of Behavioral Development, 34(4), 363-373.

Webster-Stratton, C. (1990). Stress: A potential disruptor of parent perceptions and family interactions. Journal of Clinical Child Psychology, 19(4), 302-312. 